\title{
Investing in Tobacco Control: Twelve Years of MPOWER Measures and Progress in the Western Pacific Region
}

\author{
Katia De Pinho Campos ${ }^{1,2}$, Mina Kashiwabara ${ }^{3 *}$, Ashlee Teakle ${ }^{1}$, Ramon De \\ Guzman $^{4}$, Kate Lannan4, Susan Mercado1
}

\begin{abstract}
Tobacco use has detrimental effects in the Western Pacific Region. The World Health Organization (WHO) Framework Convention on Tobacco Control (FCTC) came into effect in 2005 to address the global tobacco epidemic, and WHO introduced the MPOWER measures to facilitate implementation of key demand-reduction measures of the WHO FCTC at the country level. This paper provides an overview of progress made by countries within the Region since the introduction of the MPOWER measures 12 years ago, and examines challenges and threats hindering their further implementation.
\end{abstract}

Keywords: Tobacco- public health- noncommunicable diseases- primary prevention- health policy

Asian Pac J Cancer Prev, 21, Progress of Tobacco Control in the Western Pacific Region Suppl, 9-16

\section{Introduction}

Tobacco use, in all its forms, is one of the leading preventable risk factors of noncommunicable diseases (NCDs) and premature mortality in the world (World Health Organization [WHO], 2008). The Western Pacific Region is home to one third of the world's smokers, with five people dying every minute from tobacco-related disease (WHO, 2018; Institute for Health Metrics and Evaluation, 2019). It is estimated that half of all men, women and children within the Region are regularly exposed to second-hand smoke (SHS) in public places and at home (Oberg et al., 2011).

The World Health Organization (WHO) Framework Convention on Tobacco Control (FCTC), which came into effect in 2005, is the first global public health treaty developed by countries in response to the urgent need to curb the tobacco epidemic. The treaty is an evidence-based instrument that contains measures to reduce both supply and demand of tobacco, and reaffirms the right of all people to the highest standard of health (WHO, 2003). In 2008, WHO introduced the MPOWER measures to assist countries in the implementation of effective interventions to reduce tobacco use (WHO, 2008). The six proven policies that can reverse the tobacco epidemic and prevent millions of tobacco-related deaths include:

- Monitor tobacco use and prevention policies

- Protect people from tobacco smoke
- Offer to help quit tobacco use

- Warn about the dangers of tobacco

- Enforce bans on tobacco advertising, promotion and sponsorship; and

- Raise taxes on tobacco

Since the introduction, WHO has been monitoring and assessing the level of implementation of the MPOWER measures against the best practice level defined by WHO every two years.

The Global Action Plan has recommended a list of "best buys", which are the most cost-effective and affordable policy options for preventing and controlling the four key risk factors for NCD, one of which is tobacco use. Four of the MPOWER measures, more specifically, PWER measures are included in this list of policy options to reduce tobacco use: (WHO, 2013).

The Western Pacific was the first WHO region to set a measurable reduction target for smoking and other tobacco use - a $10 \%$ reduction in relative prevalence over five years. It was first set in its Regional Action Plan 2010-2014, and again in the Regional Action Plan 2015-2019 (WHO Regional Office for the Western Pacific [WHO WPRO], 2009; WHO WPRO, 2015). These targets are consistent with the WHO Global Action Plan for the Prevention and Control of Noncommunicable Diseases 2013-2020 (Global Action Plan), which calls for a 30\% relative reduction in prevalence of current tobacco use in persons aged 15 years and above by 2025 (WHO, 2013).

${ }^{1}$ (Former) Division of NCD and Health though the Life-Course, World Health Organization Regional Office for the Western Pacific, Manila, Philippines. ${ }^{2}$ Pan American Health Organization, Representative Office, Brasilia, Brazil. ${ }^{3}$ Division of Healthy Environments and Populations, World Health Organization Regional Office for the Western Pacific, Manila, Philippines. ${ }^{4}$ (Former) Division of Healthy Environments and Populations, World Health Organization Regional Office for the Western Pacific, Manila, Philippines.*For Correspondence: kashiwabaram@who.int 
These regional and global action plans provide practical recommendations to guide Member States in accelerating and/or strengthening implementation of the WHO FCTC and MPOWER measures. These action plans will contribute to the realization of the Sustainable Development Goals, particularly Goal 3, which seeks to "ensure healthy lives and promote well-being for all at all ages". Target 3 . specifically calls on countries to strengthen the implementation of the WHO FCTC in all countries, as appropriate.

This article aims to highlight the progress of implementation of the MPOWER measures over the past 12 years in 27 countries in the Western Pacific Region. It also identifies challenges and emerging threats to further implementing the MPOWER measures.

\section{Tobacco Use and Patterns}

Smoked tobacco includes cigarettes, pipe tobacco, loose tobacco and waterpipe tobacco, and is the most commonly used form of tobacco across the Region. Between 2000 and 2015, WHO estimated that the Western Pacific Region observed a 17\% reduction in the overall smoking rate, from $29.9 \%$ to $24.8 \%$ (WHO, 2018). According to the latest national surveys in the 27 countries in the Region, in almost all countries, smoking rates among men are remarkably higher than for women. The gender gap is particularly wide in Cambodia, China, Malaysia, Vanuatu and Viet Nam, where smoking prevalence is 14, 19, 33, 11 and 41 times higher among men when compared to women, respectively. Nauru is the only country with a reversed gender gap in the Region, with female prevalence exceeding male prevalence by $2 \%$ (Table 1 ).

The smoking patterns among youth in the Region tell a slightly different story with the gender gap in adolescents being significantly narrower than the gap between adult men and women (Table 1). In some countries, smoking rates for female adolescents exceeds that of male adolescents. For instance, in New Zealand, the smoking rate for girls is $20 \%$ higher than the rate for boys, while the smoking rate among adult women is $19 \%$ lower than that for men.

Data also suggest that countries with low adult smoking prevalence (i.e. less than 20\%) tend to fall into the high-income category, while countries with high smoking prevalence (i.e. greater than $30 \%$ ) are most likely to be in the middle-income category. Similar patterns are observed among adolescent populations (Table 1).

Smokeless tobacco such as snuff and chewing tobacco are also commonly used across the Region (Table 2). In some countries, tobacco is chewed together with another addictive substance such as areca nut (also referred to as betel nut) (WHO WPRO, 2012). Whilst data are limited, it is worth noting that smokeless tobacco use exceeds smoking rates in some countries. For instance, in Palau, prevalence of smokeless tobacco is twice the smoking rate both among adults and youth. Data also show that smokeless tobacco use is higher among women in some countries within the Region, including Brunei Darussalam, Cambodia, the Lao People's Democratic Republic, Palau and Viet Nam.

\section{Progress of MPOWER Measures}

The following section highlights progress made by countries in each of the MPOWER measures over the past 12 years from 2007 (i.e. the year before the introduction of MPOWER) to 2018.

\section{Monitoring Tobacco Use and Prevention Policies}

Monitoring is an essential aspect of tobacco control. It allows for the collection of data to help raise awareness of the problem, understand trends in tobacco use and plays an integral role in decision making and evaluation of tobacco control measures implemented in a country. As best practice, WHO recommends that countries collect nationally representative tobacco use estimates for both adults and youth with at least two time-points with an interval of five years or less.

As of December 2018, 14 of the 27 countries in the Region have achieved the best practice level for the $M$ measure (Figure 1). This is a threefold increase since 2007 (WHO, 2009; WHO, 2019). Many of these "best practice" countries have established their own tobacco surveillance mechanisms. For instance, Japan has been monitoring adult tobacco use since 1983 as part of a wider health survey (Committee on Health Impact of Smoking, 2016). In New Zealand, its health survey was first carried out intermittently from 1992 until it became an annual survey in 2011; the survey tracks smoking patterns, among other health indicators.

The Pacific island countries (PICs) have made important progress despite logistical challenges. PICs are generally composed of a number of islands spread across vast areas, posing challenges for conducting national surveys, such as the need for additional financial and human resources. Despite this, two of the 14 best practice countries are from the Pacific - Cook Islands and Palau. Cook Islands, for example, in addition to health-specific surveys, collects tobacco use data through its census conducted every five years. This has allowed the country to regularly monitor tobacco use without needing to invest additional resources on tobacco-specific (or public health) surveys.

Standardized global surveillance mechanisms have significantly facilitated progress in monitoring tobacco use in the Region. Examples of surveillance mechanisms include the Global Tobacco Surveillance System (GTSS), which encompasses Tobacco Questions for Surveys (TQS), Global Adult Tobacco Survey (GATS) and Global Youth Tobacco Survey (GYTS). These surveillance mechanisms were developed in the late 1990s/early 2000s by WHO, the United States Centers for Disease Control and Prevention (CDC) and other partners. Other global surveillance tools commonly used to monitor tobacco use include the WHO STEPwise Approach to Surveillance (STEPS) and Global School-based Student Health Surveys (GSHS). Their purpose is to assist countries in systematically collecting health data that can be compared over time and across countries. While GATS, GYTS, STEPS and GSHS are designed to be implemented as standalone surveys, TQS - which contains a subset of key questions from GATS - was designed to be included in any national survey. Its purpose is to promote data comparability using existing 
DOI:10.31557/APJCP.2020.21.S1.9

Table 1. Current Tobacco Smoking by Country, most Recent National Survey

\begin{tabular}{|c|c|c|c|c|c|c|c|c|c|c|}
\hline \multirow[t]{2}{*}{ Country } & \multicolumn{10}{|l|}{ Adult } \\
\hline & Survey, Year & Age & Overall & Men & Women & Survey, Year & Age & Overall & Boys & Girls \\
\hline Australia & $\begin{array}{l}\text { National } \\
\text { Drug Strategy } \\
\text { Household } \\
\text { Survey, 2016 }\end{array}$ & $14+$ & 12.2 & 13.8 & 10.7 & $\begin{array}{l}\text { Australian Secondary } \\
\text { School Students } \\
\text { Alcohol and Drug } \\
\text { Survey, 2014 }\end{array}$ & $12-17$ & 5.1 & 5.4 & 4.9 \\
\hline Brunei Darussalam & STEPS, 2016 & $18-69$ & 19.9 & 36.3 & 3.7 & GSHS, 2014 ${ }^{\mathrm{b}}$ & $13-17$ & 11.4 & 17.8 & 4.8 \\
\hline Cambodia & $\begin{array}{l}\text { National Adult } \\
\text { Tobacco Survey } \\
\text { of Cambodia, } \\
2014\end{array}$ & $15+$ & 16.9 & 32.9 & 2.4 & GYTS, 2016 & $13-15$ & 1.5 & 1.8 & 1.2 \\
\hline China & $\begin{array}{l}\text { Adult Tobacco } \\
\text { Survey, } 2015\end{array}$ & $15+$ & 27.7 & 52.1 & 2.7 & GYTS, 2014 & $13-15$ & 6.4 & 10.6 & 1.8 \\
\hline Cook Islands & STEPS, 2014 & $18-64$ & 32.6 & 37.9 & 27.7 & GYTS, 2016 & $13-15$ & 20.7 & 28.1 & 13.9 \\
\hline Fiji & STEPS, 2011 & $25-64$ & 30.7 & 47 & 14.3 & GYTS, 2016 & $13-15$ & 7.6 & 9.6 & 5.5 \\
\hline Japan & $\begin{array}{l}\text { National Health } \\
\text { and Nutrition } \\
\text { Survey, } 2017^{\mathrm{b}}\end{array}$ & $20+$ & 17.7 & 29.3 & 7.2 & $\begin{array}{l}\text { National Survey on } \\
\text { Underage Smoking } \\
\text { and Drinking, } 2017^{\mathrm{n}}\end{array}$ & $\begin{array}{l}\text { Junior- } \\
\text { High }\end{array}$ & 0.6 & 0.7 & 0.5 \\
\hline Kiribati & $\begin{array}{l}\text { STEPS, 2015- } \\
2016\end{array}$ & $18-69$ & 47.7 & 64.7 & 33.4 & GSHS, $2014^{\mathrm{n}}$ & $13-15$ & 26.1 & 34.3 & 19.5 \\
\hline $\begin{array}{l}\text { Lao People's } \\
\text { Democratic Republic }\end{array}$ & $\begin{array}{l}\text { National } \\
\text { Adult Tobacco } \\
\text { Survey, } 2015\end{array}$ & $15+$ & 27.9 & 50.8 & 7.1 & GYTS, 2016 & $13-15$ & 8.1 & 12.9 & 3.3 \\
\hline Malaysia & $\begin{array}{l}\text { National Health } \\
\text { and Morbidity } \\
\text { Survey, } 2015\end{array}$ & $15-75$ & 22.6 & 42.5 & 1.3 & $\begin{array}{l}\text { National Health and } \\
\text { Morbidity Survey - } \\
\text { Adolescent Health } \\
\text { Survey, } 2017\end{array}$ & $13-17$ & 15.9 & 25.3 & 6.7 \\
\hline Marshall Islands & STEPS, 2002 & $15-64$ & 23.1 & 39.5 & 6 & GYTS, 2016 & $13-15$ & 19.3 & 27.7 & 12.3 \\
\hline $\begin{array}{l}\text { Micronesia, Federated } \\
\text { States of }\end{array}$ & $\begin{array}{l}\text { National } \\
\text { Outcome } \\
\text { Measures } \\
\text { Survey, 2012 }\end{array}$ & Dec-98 & 62.4 & 69.1 & 46.9 & GYTS, 2013 & $13-15$ & 33 & 43 & 24.4 \\
\hline Mongolia & STEPS, 2013 & $15-64$ & 27.1 & 49.1 & 5.3 & GYTS, 2014 & $13-15$ & 5.6 & 8.2 & 2.9 \\
\hline Nauru & $\begin{array}{l}\text { STEPS, 2015- } \\
2016\end{array}$ & $18-69$ & 46.3 & 47.4 & 45.3 & GSHS, $2011^{\mathrm{b}}$ & $13-15$ & 22.1 & 19.5 & 24.5 \\
\hline New Zealand & $\begin{array}{l}\text { New Zealand } \\
\text { Health Survey, } \\
\text { 2017-2018 }\end{array}$ & $15+$ & 14.9 & 16.4 & 13.3 & $\begin{array}{l}\text { ASH Year } 10 \text { Survey, } \\
2018\end{array}$ & $14-15$ & 5 & 4.5 & 5.4 \\
\hline Niue & STEPS, 2011 & $15+$ & 17.7 & 22.6 & 13 & GSHS, 2010b & $13-15$ & 16.1 & 23.3 & $\ldots$ \\
\hline Palau & $\begin{array}{l}\text { Palau Hybrid } \\
\text { Survey, } 2016\end{array}$ & $18-97$ & 20.4 & 30.9 & 9.7 & GYTS, 2017 & $13-15$ & 35.4 & 42.3 & 28.8 \\
\hline Papua New Guinea & $\begin{array}{l}\text { Household } \\
\text { Income \& } \\
\text { Expenditure } \\
\text { Survey, 2009- } \\
2010\end{array}$ & $0+$ & 26.3 & 37.3 & 14.5 & GYTS, 2016 & $13-15$ & 25.4 & 34.9 & 18.2 \\
\hline Philippines & GATS, 2015 & $15+$ & 22.7 & 40.3 & 5.1 & GYTS, 2015 & $13-15$ & 14.5 & 20.5 & 9.1 \\
\hline Republic of Korea & $\begin{array}{l}\text { Korea National } \\
\text { Health and } \\
\text { Nutrition } \\
\text { Examination } \\
\text { Survey, 2017 }\end{array}$ & $19+$ & 21.1 & 37 & 5.2 & $\begin{array}{l}\text { Korea Youth Risk } \\
\text { Behavior Web-based } \\
\text { Survey, 2018 }\end{array}$ & $13-18$ & 6.7 & 9.4 & 3.7 \\
\hline Samoa & STEPS, 2013 & $18-64$ & 25.6 & 36.5 & 13.7 & GYTS, 2017 & $13-15$ & 13 & 19.9 & 6.5 \\
\hline Singapore & $\begin{array}{l}\text { National } \\
\text { Population } \\
\text { Health Survey, } \\
\text { 2016-2017 }\end{array}$ & $18-69$ & 12 & 21.1 & 3.4 & $\begin{array}{l}\text { Student Health } \\
\text { Survey, 2014-2016 }\end{array}$ & $13-20$ & 4.3 & $\ldots$ & $\ldots$ \\
\hline Solomon Islands & $\begin{array}{l}\text { Demographic } \\
\text { and Health } \\
\text { Survery, 2015 }\end{array}$ & $15-49$ & $\ldots$ & 49.8 & 17 & GSHS, $2011^{\mathrm{b}}$ & $13-15$ & 24 & 28.3 & 18.4 \\
\hline Tonga & STEPS, 2017 & $18-69$ & 24.5 & 40 & 15.9 & GSHS, $2017^{\mathrm{b}}$ & $13-15$ & 14.6 & 22.1 & 6.8 \\
\hline Tuvalu & STEPS, 2015 & $18-69$ & 35 & 48.6 & 22.4 & GSHS, $2013^{\mathrm{b}}$ & $13-15$ & 15.9 & 27.2 & 5.6 \\
\hline Vanuatu & STEPS, 2011 & $25-64$ & 23.7 & 45.8 & 4 & GYTS, 2017 & $13-15$ & 14.1 & 16.7 & 11.7 \\
\hline Viet Nam & GATS, 2015 & $15+$ & 22.5 & 45.3 & 1.1 & GYTS, 2014 & $13-15$ & 3.5 & 6.3 & 0.9 \\
\hline
\end{tabular}

a , Daily cigarette smoking; ${ }^{b}$, Current cigarette smoking; ${ }^{c}$, Daily tobacco smoking; ..., No data available or reported in the WHO report on the global tobacco epidemic 2019; STEPS, the WHO STEPwise Approach to Surveillance; GATS, Global Adult Tobacco Survey; GSHS, Global School-based Student Health Surveys; GYTS, Global Youth Tobacco Survey 
Table 2. Current Smokeless Tobacco Use by Country, most Recent National Survey

\begin{tabular}{|c|c|c|c|c|c|c|c|c|c|c|}
\hline \multirow[t]{2}{*}{ Country } & \multicolumn{5}{|l|}{ Adult } & \multicolumn{5}{|l|}{ Youth } \\
\hline & Survey, Year & Age & Overall & Men & Women & Survey, Year & Age & Overall & Boys & Girls \\
\hline Australia & $\begin{array}{l}\text { National Drug Strategy } \\
\text { Household Survey, } 2013\end{array}$ & $14+$ & 0.4 & 0.6 & 0.3 & $\ldots$ & $\ldots$ & $\ldots$ & $\ldots$ & $\ldots$ \\
\hline $\begin{array}{l}\text { Brunei } \\
\text { Darussalam }\end{array}$ & STEPS, 2016 & $18-69$ & 1.9 & 1.7 & 2.1 & GYTS, 2013 & $13-15$ & 0.9 & 1.2 & 0.7 \\
\hline Cambodia & $\begin{array}{l}\text { National Adult Tobacco } \\
\text { Survey of Cambodia, } \\
2014\end{array}$ & $15+$ & 4.9 & 0.8 & 8.6 & GYTS, 2016 & $13-15$ & 1 & 1.3 & 0.8 \\
\hline China & $\ldots$ & $\ldots$ & $\ldots$ & $\ldots$ & $\ldots$ & GYTS, 2014 & $13-15$ & 1 & 1.3 & 0.6 \\
\hline Cook Islands & $\ldots$ & $\ldots$ & $\ldots$ & $\ldots$ & $\ldots$ & GYTS, 2016 & $13-15$ & 3 & 3.8 & 2.4 \\
\hline Fiji & $\ldots$ & $\ldots$ & $\ldots$ & $\ldots$ & $\ldots$ & GYTS, 2016 & $13-15$ & 2.1 & 2.6 & 1.5 \\
\hline Kiribati & STEPS, 2015-2016 & $18-69$ & 4.2 & 7.6 & 1.4 & $\ldots$ & $\ldots$ & $\ldots$ & $\ldots$ & $\ldots$ \\
\hline $\begin{array}{l}\text { Lao People's } \\
\text { Democratic } \\
\text { Republic }\end{array}$ & $\begin{array}{l}\text { National Adult Tobacco } \\
\text { Survey, } 2015\end{array}$ & $15+$ & 4.3 & 0.5 & 8.6 & GYTS, 2016 & $13-15$ & 3.8 & 4.8 & 2.8 \\
\hline Malaysia & $\begin{array}{l}\text { National Health and } \\
\text { Morbidity Survey, } 2015\end{array}$ & $15-75$ & 10.9 & 20.4 & 0.8 & $\begin{array}{l}\text { National Health and } \\
\text { Morbidity Survey - } \\
\text { Adolescent Health } \\
\text { Survey, } 2017\end{array}$ & $13-17$ & 6.3 & 8.2 & 3.2 \\
\hline $\begin{array}{l}\text { Marshall } \\
\text { Islands }\end{array}$ & STEPS, 2002 & $15-64$ & 8.9 & 13.7 & 4 & GYTS, 2016 & $13-15$ & 14.9 & 18.9 & 11.8 \\
\hline $\begin{array}{l}\text { Micronesia, } \\
\text { Federated } \\
\text { States of }\end{array}$ & $\ldots$ & $\ldots$ & $\ldots$ & $\ldots$ & $\ldots$ & GYTS, 2013 & $13-15$ & 23.8 & 26.4 & 21.7 \\
\hline Mongolia & STEPS, 2013 & $15-64$ & 0.5 & 0.8 & 0.2 & GYTS, 2014 & $13-15$ & 9.5 & 13.6 & 5.7 \\
\hline Nauru & STEPS, 2015-2016 & $18-69$ & 0.1 & 0.2 & $\ldots$ & $\ldots$ & $\ldots$ & $\ldots$ & $\ldots$ & $\ldots$ \\
\hline Niue & STEPS, 2011 & $15+$ & 0.2 & 0.3 & 0.2 & GYTS, 2009 & $13-15$ & 8.6 & 9 & 7.9 \\
\hline Palau & $\begin{array}{l}\text { Palau Hybrid Survey, } \\
2016\end{array}$ & $18-97$ & 44.4 & 40.2 & 48.8 & GYTS, 2017 & $13-15$ & 14.7 & 12.2 & 16.8 \\
\hline $\begin{array}{l}\text { Papua New } \\
\text { Guinea }\end{array}$ & $\ldots$ & $\ldots$ & $\ldots$ & $\ldots$ & $\ldots$ & GYTS, 2016 & $13-15$ & 12.2 & 10.9 & 13.6 \\
\hline Philippines & GATS, 2015 & $15+$ & 1.7 & 2.7 & 0.7 & GYTS, 2015 & $13-15$ & 2.5 & 2.9 & 2.1 \\
\hline Samoa & STEPS, 2013 & $18-64$ & 0.9 & 1.3 & 0.5 & GYTS, 2017 & $13-15$ & 2.1 & 2.9 & 1.5 \\
\hline $\begin{array}{l}\text { Solomon } \\
\text { Islands }\end{array}$ & STEPS, 2015 & $18-69$ & 3.4 & 4 & 2.9 & $\ldots$ & $\ldots$ & $\ldots$ & $\ldots$ & $\ldots$ \\
\hline Vanuatu & STEPS, 2011 & $25-64$ & 0.9 & 1.8 & 0.2 & GYTS, 2017 & $13-15$ & 5.2 & 5.9 & 4.6 \\
\hline Viet Nam & GATS, 2015 & $15+$ & 1.4 & 0.8 & 2 & GYTS, 2014 & $13-15$ & 0.7 & 1 & 0.4 \\
\hline
\end{tabular}

No data available either for adults or youth for Japan, New Zealand, Republic of Korea Singapore, Tonga, and Tuvalu in the WHO report on the global tobacco epidemic 2019; STEPS, the WHO STEPwise Approach to Surveillance; GATS, Global Adult Tobacco Survey; GSHS, Global School-based Student Health Surveys; GYTS, Global Youth Tobacco Survey.

national surveillance mechanisms. In some cases, these surveys are adapted to the national context; for instance, Cambodia adopted GATS with a modified sampling method to accommodate existing national capacity and implemented two rounds of that survey to collect comprehensive information on tobacco use and control in the country. Almost all Member States in the Region (24 out of 27) have implemented one of the above-mentioned surveys over the past 12 years. In many of these countries, these surveys are the only source of tobacco use data.

\section{Protecting People from Tobacco Smoke}

There is no safe level of exposure to SHS. To effectively protect people from SHS, WHO recommends that governments implement comprehensive smoke-free laws covering all indoor public places, workplaces and public transport, without exception. This includes the prohibition of designated smoking rooms or areas.
As of December 2018, nine countries have implemented best practice smoke-free policies. Best practice means that all public places are completely smoke-free or that at least $90 \%$ of the population is covered by comprehensive subnational smoke-free laws. There has been significant progress in this measure over the last 12 years (WHO, 2019). In 2007, there were only three countries in the Region with best practice smoke-free policies - Australia, Marshall Islands and New Zealand (Figure 1) (WHO, 2008). Since then, Brunei Darussalam, Cambodia, Lao People's Democratic Republic, Nauru, Niue and Papua New Guinea have introduced smoking bans in all public places.

Health care facilities are the best protected indoor public space across the Region, with 23 countries mandating that these be smoke-free through legislation, followed by public transport (21 countries), government facilities (20 countries) and educational facilities with the 


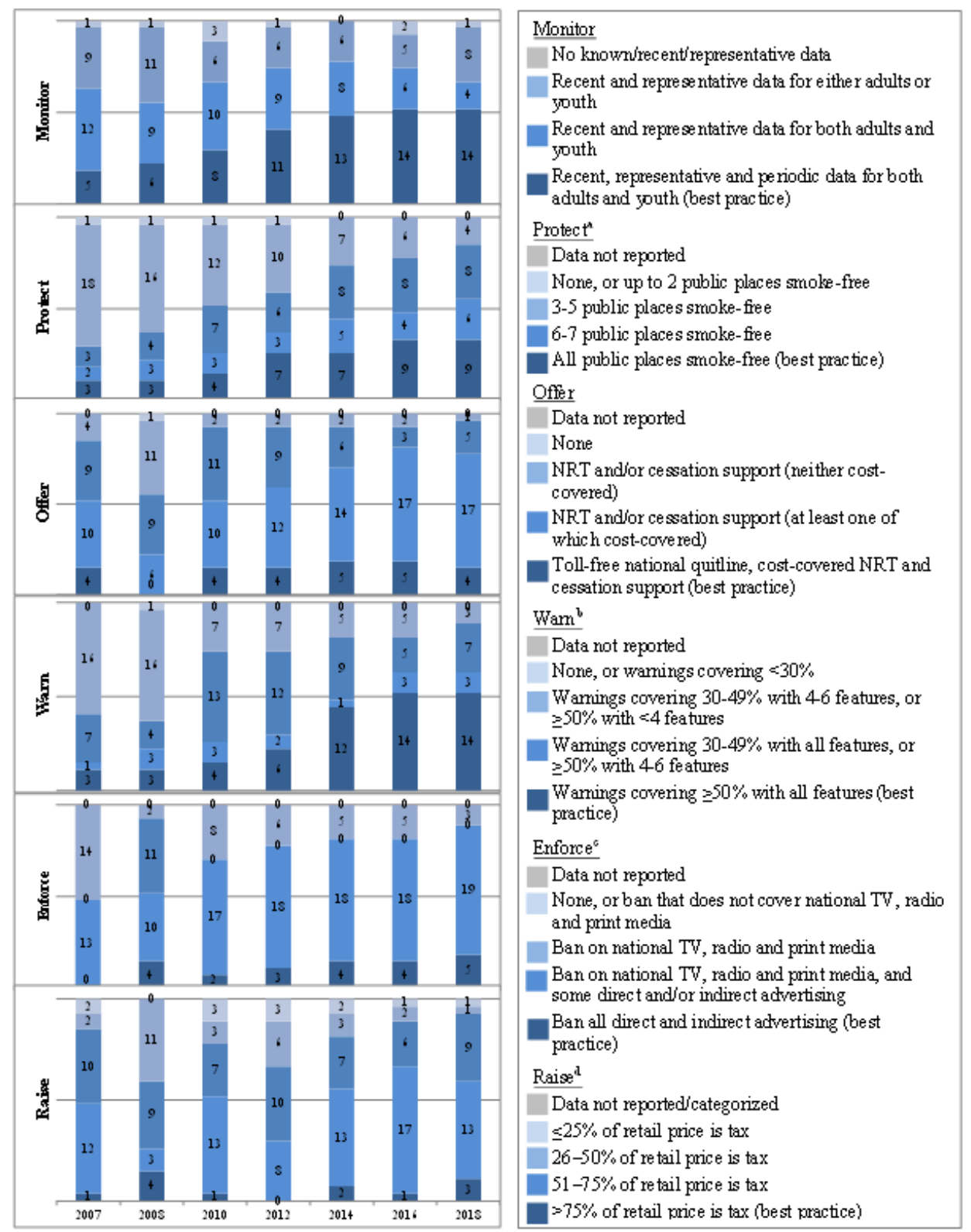

Figure 1. Status of MPOWER Measures by Country, 2007-2018. a, Types of public places: health-care facilities; educational facilities other than universities; universities; government facilities; indoor offices and workplaces not considered in any other category; restaurants; cafés, pubs and bars; and public transport; The best practice category includes when $90 \%$ of the country's population are covered by subnational laws. ${ }^{\text {b }}$, Proportion indicates the average of front and back display areas of package; Features include: specific health warnings mandated; appearing on individual packages as well as on any outside packaging and labelling used in retail sale; describing specific harmful effects of tobacco use on health; are large, clear, visible and legible (e.g. specific colours and font style and sizes are mandated); rotate; include pictures or pictograms; and written in (all) the principal language(s) of the country. ${ }^{\mathrm{c}}$, Direct advertising bans include national television and radio, local magazines and newspapers, billboards, and outdoor advertising and point of sale (indoor); Indirect advertising bans include free distribution of tobacco products in the mail or through other means, promotional discounts, non-tobacco products identified with tobacco brand names (brand stretching), brand names of non-tobacco products used for tobacco products (brand sharing), appearance of tobacco brands (product placement) or tobacco products in television and/or films, and sponsorship (contributions and/or publicity of contributions); The best practice category includes when $90 \%$ of the country's population are covered by subnational laws; ${ }^{\mathrm{d}}$, Proportion indicates the total taxes in the retail price of the most sold brand of cigarettes.

exception of universities (20 countries) (WHO, 2019). Pubs and bars are the least protected indoor area with only 12 countries mandating these as smoke-free.

While national smoke-free laws are preferred for maximum impact, the role of subnational governments must not be overlooked (Yan, 2008). Mayors and other subnational leaders are increasingly taking steps to introduce local smoking bans in instances of weak or absent smoke-free polices at the national level. In China, for example, Beijing, Lanzhou, Shanghai, Shenzhen and Xi'an - with populations totalling 67 million - passed comprehensive smoke-free laws between 2014 and 2018. Without the introduction of these laws, the residents of these cities would still be exposed to SHS.

Site-specific interventions have positively contributed to the expansion of smoke-free environments. Many of 
the Region's mega sports events - such as the Olympic Games, Pacific Games and Southeast Asian Games - have been declared smoke-free in a bid to promote healthy environments (Yan, 2008; WHO WPRO, 2010). It is worth noting that since 1988, every Olympic Games has been declared smoke-free. This includes the Beijing Olympics in 2008 that was the impetus for the development of Beijing's broader 10-year health plan, "Healthy Beijing Residents". The plan included a commitment to strengthening tobacco control and led to the enactment of Beijing's comprehensive smoke-free law in 2014 (Southeast Asia Tobacco Control Alliance [SEATCA], 2013).

Another important site-specific approach to smoke-free policies is to implement these measures in major tourist areas or attractions, such as World Heritage Sites, national parks and beaches. In 2011, the Southeast Asia Tobacco Control Alliance (SEATCA) convened a regional workshop calling for cities and heritage sites in the Association of Southeast Asian Nations (ASEAN) countries to become smoke-free (SEATCA, 2013). This was to ensure the protection of people from SHS, in addition to preventing fires and environmental damage caused by tobacco use. Since then, a number of World Heritage Sites and the cities in which they are located are now smoke-free, including Angkor sites in Cambodia, Luang Prabang in the Lao People's Democratic Republic, Penang in Malaysia and Ha Long in Viet Nam (SEATCA, 2013).

\section{Offering to Help Quit Tobacco Use}

Nicotine in tobacco products is an addictive drug that causes tobacco users to develop dependency. As part of the $\mathrm{O}$ measure, WHO recommends that access to cessation support be a crucial component to helping users overcome tobacco dependence. Best practice in cessation requires availability of three important services: (1) a toll-free national quitline; (2) cost-covered nicotine replacement therapy (NRT); and (3) other cost-covered cessation support.

As of 2016, the $\mathrm{O}$ best practice measure has been implemented in four countries, including Australia, New Zealand, the Republic of Korea and Singapore (Figure 1) (WHO, 2019). Meanwhile, the number of countries that offer cost-covered NRT and/or cessation service (i.e. best practice measures, lacking only a toll-free national quitline) has increased steadily from 10 in 2007 to 17 in 2018 (WHO, 2008); WHO, 2019).

As countries strengthen their tobacco control policies, demand for cessation support increases. This includes technical support by governments to establish smoking cessation programmes. Since 2013, the WHO Collaborating Centre for Smoking Cessation and Treatment of Tobacco Dependence, Tobacco Control Office, Department of Health, Hong Kong SAR (China), has trained several government officials and health-care professionals across the Region on smoking cessation. Training is run through the annual fellowship programme and focuses on the development and evaluation of cessation programmes.

The use of mobile technology has also been used to support smoking cessation and has been of increasing interest to countries across the Region. Early experiences suggest that mCessation - as it is referred to in the Region - is a cost-effective tool to support smokers to quit their deadly habit (Guerriero et al., 2013). The Philippines, for example, was the first country in the Region to launch mCessation services as part of its National Quitline Programme (Republic of the Philippines Department of Health [DOH Philippines], 2017). Taking advantage of the number of people who have access to mobile phones in the Philippines, the mCessation service provides Filipinos, including those living in remote areas, with cheap yet reliable support to help them quit smoking (DOH Philippines, 2017).

\section{Warning about the Dangers of Tobacco}

Health warnings are an effective measure to communicate risks of using tobacco and encourage quitting, and should be placed on all tobacco packages. Best practice for the $\mathrm{W}$ measure requires specific health warnings to be mandated by law, and for the warnings to cover at least $50 \%$ of the front and back display areas of cigarette packs.

Health warnings are an increasingly popular measure in the Region. The number of $\mathrm{W}$ best practice countries increased from three in 2007 to 14 in 2019 (Figure 1) (WHO, 2008; WHO, 2019). These countries include Australia, Brunei Darussalam, Cambodia, Fiji, Lao People's Democratic Republic, Malaysia, Mongolia, New Zealand, Philippines, Samoa, Singapore, Solomon Islands, Vanuatu and Viet Nam. All 14 countries have required that all cigarette packages carry health warnings that meet the best practice measures.

The world's first plain packaging (i.e. tobacco packs with no logos, brand images or promotional information other than brand names and product names in a standardized format and colours) was introduced in Australia in 2012. New Zealand also introduced plain packaging in 2018, and Singapore is set to implement this by 2020 . Fiji, Samoa, Solomon Islands and Vanuatu became the first PICs to introduce best practice health warnings in 2013. In 2016, Vanuatu implemented one of the largest pictorial health warnings in the world, covering 95\% of cigarette packs. In the same year, the Lao People's Democratic Republic adopted the Region's second largest pictorial warnings, covering $85 \%$ of cigarette packs.

\section{Enforcing Bans on Tobacco Advertising, Promotion and Sponsorship}

To effectively reduce tobacco use, all forms of tobacco advertising, promotion and sponsorship must be banned. In this regard, best practice for the E measure includes a ban on all forms of direct and indirect tobacco advertising. Alternatively, if there is no national ban, at least $90 \%$ of the population is required to be covered by complete bans on advertising at a subnational level.

Progress in this area has been relatively slow in the Region. The first two countries to ban all forms of advertising were Tuvalu and Vanuatu, both of which adopted the comprehensive ban in 2008 (Figure 1) (WHO, 2019). Following these two PICs, Mongolia, Kiribati and 
Niue adopted this best practice in 2012, 2013 and 2018, respectively.

Traditional direct advertising uses television, radio, print media and billboards, and is being banned in an increasing number of countries. While 15 out of 27 countries in the Region have banned direct advertising, indirect advertising, which refers to promotion and sponsorship, is still prevalent in many of these countries (WHO, 2019). As of 2018, only Kiribati, the Lao People's Democratic Republic and Mongolia have comprehensive bans on sponsorship, that is any form of contribution by the tobacco industry, even when it is done anonymously, are banned. Brand stretching - using tobacco brand names on non-tobacco products such as clothes - is banned in 19 countries.

\section{Raising Taxes on Tobacco}

Raising tobacco taxes to reduce affordability of tobacco products is the most cost-effective measure to save lives, reduce poverty and increase countries' domestic resources (WHO, 2010; United Nations, 2015; WHO, 2017). A 2016 study has shown that if countries around the world increased excise taxes by US $\$ 0.80$ per cigarette pack, the amount of excise revenue generated will produce an extra US\$ 141 billion. Additionally, smoking prevalence will be reduced by $9 \%$ (or 66 million smokers) and smoking-attributable deaths will decline by $6 \%$ (or 15 million) among the world's adult population (Goodchild et al., 2016). For the Western Pacific Region, the increase of excise tax by US $\$ 0.80$ per cigarette pack will translate to the prevention of 7 million premature deaths (Goodchild et al., 2016).

WHO best practice in regard to the $\mathrm{R}$ measure involves increasing the total tobacco taxation rate to more than $75 \%$ of the retail price of tobacco products. According to the WHO reports on the global tobacco epidemic (2008; 2009 ; 2011;2013; 2015; 2017; 2019), between 2007 and 2018 , R best practice was only achieved by Australia, New Zealand and Niue (Figure 1). As of July 2018, tobacco taxes in Australia, New Zealand and Niue respectively account for $77.5 \%, 82.2 \%$ and $87.7 \%$ of the retail price of each country's most sold cigarette brand. However, due to other factors such as changes in the production cost and the most sold brand, these countries did not achieve the best practice level of taxation rate consistently throughout the 12 years. In 2018, Cook Islands, Palau, Philippines and Republic of Korea have achieved more than 70\%; however, their taxation levels have yet to reach the best practice level (WHO, 2019).

\section{Challenges and ways forward}

Tobacco use is one of the biggest preventable causes of premature death worldwide, killing over 8 million people each year. Its economic costs are also enormous, totalling more than US\$ 1.4 trillion in health-care costs and lost productivity (Goodchild et al.; 2016). The Western Pacific Region is no exception.

A dramatic change in tobacco control has been observed in the Western Pacific Region over the past 12 years. While the level of progress made varies across the MPOWER measures, countries are increasingly taking the necessary steps towards implementation of best practice measures. The introduction of global surveillance mechanisms such as GTSS, STEPS and GSHS have greatly contributed to the wider availability of data. Data have shown that while smoking rates are decreasing in many countries in the Region, smokeless tobacco use remains highly prevalent in some countries. Furthermore, the significant gender gap in tobacco use persists in adult populations, while the gap between boys and girls is narrowing. Tobacco control measures should be responsive to these gender differences.

Surveillance must also take into account the evolving nature of tobacco products, with waterpipe tobacco, smokeless tobacco and heated tobacco products becoming increasingly accessible across the Region. Electronic nicotine delivery systems (ENDS), including e-cigarettes and vaping devices, for example, are being aggressively marketed in a number of countries. Countries must adapt to these changes to ensure that all forms of tobacco use and other products that may undermine tobacco control gains are addressed to ensure tobacco control measures are effectively implemented.

This paper also highlights the possibility for countries - including the small islands dispersed across the Pacific - to conduct periodic monitoring of tobacco use without relying exclusively on external financial support but by taking advantage of existing regular national surveys.

Efforts to expand smoke-free environments must be strengthened to protect workers and members of the general public from the harmful effects of tobacco smoke. People are still exposed to SHS in two thirds of countries within the Region. This includes exposure in health-care facilities, where health should be the utmost priority, as well as in pubs and bars. Countries must do more to require the introduction of smoke-free policies in these indoor places.

Mobile cessation tools have great potential to contribute to tobacco control and play an increasingly valuable role in expanding the reach of cessation support to those who are willing to quit smoking. This allows appropriate support to expand beyond the health system, tothose living in hard to reach areas and other vulnerable populations such as youth.

The best practice of having large graphic health warnings on tobacco products is being adopted by an increasing number of countries across the Region. Several countries have adopted or are considering an even stronger approach by introducing plain packaging. While this paper looked at the health warnings on cigarette packages, although it should be noted that health warnings - at the best practice level - must be applied to all tobacco products, not just to cigarette packaging. This is particularly important given the changing market of tobacco products and the promotion of new products by the tobacco industry.

Despite progress in direct advertising bans, indirect advertising is not yet prohibited in many countries in the Region. The tobacco industry is using this to their advantage and in doing so, is compromising tobacco control efforts in the Region (WHO, 2017). For any ban 
on tobacco to be effective, all forms of tobacco advertising must be prohibited.

Finally, this report highlighted that there is still a long way to go in implementing best practice $\mathrm{R}$ measures. Even for countries that have achieved best practice, there is a need to continually reassess tobacco taxes to ensure tax rates keep pace with the changing prices of tobacco products and with inflation. This is crucial to reduce the affordability of tobacco products. Introducing higher tobacco taxes is often a contentious process, with countries facing strong opposition from the tobacco industry. WHO, civil society, academics and other relevant stakeholders must continue to work together to support countries in strengthening their actions and arguments to overcome interference from the tobacco industry.

While this paper focuses on the progress of implementation of the MPOWER measures, it must be noted that strong policy also requires enforcement measures. This is an essential component of successful tobacco control because it ensures compliance, which in turn contributes to a reduction in tobacco use and subsequent improvements in health and wellbeing.

The war on tobacco is not yet over and much remains to be done. The efforts of countries must be scaled up to ensure the future success of the Western Pacific Region in curbing the tobacco epidemic. We owe it to the people of our Region to protect them from the harms of tobacco.

\section{Acknowledgments}

\section{Statement conflict of Interest}

The authors confirm that there are no known conflicts of interest associated with this publication and there has been no significant financial support for this work that could have influenced its outcome.

\section{References}

Committee on Health Impact of Smoking (2016). Report of the Committee on Health Impact of Smoking [in Japanese]. Ministry of Health, Labour and Welfare, Tokyo.

Goodchild A, Perucic AM, Nargis N (2016). Modelling the impact of raising tobacco taxes on public health and finance. Bull World Health Organ, 94, 250-7.

Guerriero C, Cairns J, Roberts I, et al (2013). The cost-effectiveness of smoking cessation support delivered by mobile phone text messaging: Txt2stop. Eur J Health Econ, 14, 789-97.

Institute for Health Metrics and Evaluation (2017). Global Burden of Disease. https://vizhub.healthdata.org/gbdcompare/.

Oberg M, Jaakkola MS, Woodward A, Peruga A, Prüss-Ustün A (2011). Worldwide burden of disease from exposure to secondhand smoke: a retrospective analysis of data from 192 countries. Lancet, 377, 139-46.

Republic of the Philippines Department of Health 2017. DOH opens telephone/mobile quitlines to help Filipinos quit smoking. http://www.doh.gov.ph/node/10254.

Southeast Asia Tobacco Control Alliance (2013). SEATCA's smoke-free initiative in ASEAN: sharing SEATCA's success stories and lessons learned. Southeast Asia Tobacco Control Alliance, Bangkok.

United Nations (2015). Addis Ababa Action Agenda of the Third International Conference on Financing for Development.
United Nations, New York.

World Health Organization (2003). WHO Framework Convention on Tobacco Control. World Health Organization, Geneva.

World Health Organization (2008). WHO report on the global tobacco epidemic 2008: The MPOWER package. World Health Organization, Geneva.

World Health Organization (2009). WHO report on the global tobacco epidemic 2009: Implementing smoke-free environments. World Health Organization, Geneva.

World Health Organization (2010). WHO technical manual on tobacco tax administration. World Health Organization, Geneva.

World Health Organization (2011). Making cities smoke-free. World Health Organization, Geneva.

World Health Organization (2011). WHO report on the global tobacco epidemic 2011: Warning aobut the dangers of tobacco. World Health Organization, Geneva.

World Health Organization (2013). WHO global action plan for the prevention and control of noncommunicable diseases 2013-2020. World Health Organization, Geneva.

World Health Organization (2013). WHO report on the global tobacco epidemic 2013: Enforcing bans on tobacco advertising, promotion and sponsorship. World Health Organization, Geneva.

World Health Organization (2014). WHO calls for higher tobacco taxes to save more lives. Available: http://www.who.int/ mediacentre/news/releases/2014/no-tobacco-day/en/.

World Health Organization (2015). WHO report on the global tobacco epidemic 2015: Raising taxes on tobacco. World Health Organization, Geneva.

World Health Organization (2017). WHO report on the global tobacco epidemic, 2017: Monitoring tobacco use and prevention policies. World Health Organization, Geneva.

World Health Organization (2018). WHO global report on trends in prevalence of tobacco smoking 2000-2025, second edition. Word Health Organization, Geneva.

World Health Organization (2019). WHO report on the global tobacco epidemic, 2019: Offer help to quit tobacco use. World Health Organization, Geneva.

World Health Organization Regional Office for the Western Pacific (2009). Regional action plan for the Tobacco Free Initiative in the Western Pacific (2010-2014). World Health Organization Regional Office for the Western Pacific, Manila.

World Health Organization Regional Office for the Western Pacific (2010). The health legacy of the 2008 Beijing Olympic Games: successes and recommendations. World Health Organization Regional Office for the Western Pacific, Manila.

World Health Organization Regional Office for the Western Pacific (2012). Review of areca (betel) nut and tobacco use in the Pacific: a technical report. World Health Organization Regional Office for the Western Pacific, Manila.

World Health Organization Regional Office for the Western Pacific (2015). Regional action plan for the Tobacco Free Initiative in the Western Pacific (2015-2019). World Health Organization Regional Office for the Western Pacific, Manila.

Yan L (2008). Olympic Games in China—a catalyst for smokefree environments. Tob Control, 17, 217.

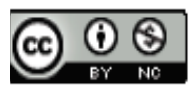

This work is licensed under a Creative Commons AttributionNon Commercial 4.0 International License. 